\title{
Evaluation Of Clinician Attitudes To The Implementation Of Novel Haemostatic Techniques
}

\author{
TJ Hodgetts, RJ Russell, PF Mahoney, MQ Russell, G Kenward
}

\section{Introduction}

Innovation in industry, stimulated by the perceived requirement of the military customer, has generated a series of recent developments in the domain of external haemorrhage control. In response to tasking from Surgeon General, the Academic Department of Military Emergency Medicine (ADMEM) has guided the operational analysis and staged implementation of three changes to improve haemostasis following injury in combat. Two of these changes involve replacement of existing equipment (a new field dressing and a new arterial tourniquet); the third change is the adoption of a haemostatic agent, QuikClot ${ }^{\mathrm{TM}}$. To enable the implementation, ADMEM developed a predeployment training programme to provide the necessary knowledge, skill and judgement to use the new products safely and effectively.

This paper evaluates the confidence of clinicians to treat life-threatening external haemorrhage before and after training in the novel techniques.

\section{Population}

The population trained for the operational analysis of the novel techniques was all the professional medical personnel (doctors, nurses, medics) deploying with the Medical Group on Operation TELIC 6 (May 2005) who attended pre-deployment clinical training at the Army Medical Services Training Centre in York.

\section{Training programme}

The training programme was 2 hours and consisted of (a) a lecture providing the evidence base for the changes in practice, including a video demonstrating the effectiveness of QuikClot ${ }^{\mathrm{TM}}$ in controlling haemorrhage in a swine model; and (b) an individual practical skill station for each new technique (bandage; tourniquet; QuikClot $\left.{ }^{\mathrm{TM}}\right)$.

Instructors had been selected from the cadre of established clinical teachers (doctors, nurses and medics) who were trained against the same materials by Professor of Emergency Medicine and given skill station lesson plans.

The lower limb traumatic amputation model was used to demonstrate and practice the bandage and tourniquet skills.
A model of a proximal lower limb wound was improvised on the training mannequins using wound simulation techniques to demonstrate and practice the use of QuikClot ${ }^{\mathrm{TM}}$.

\section{Methods}

The training programme was assessed through standardised pre-course and postcourse questionnaires, structured to avoid response set bias and tested for content validity. The pre-course questionnaire collected data on career employment group, previous training, and both current practice and confidence with the existing equipment. The post-course questionnaire sought opinions on the effectiveness of the new equipment and any perceived change in confidence to manage severe external haemorrhage. Following collation of the responses, the results were analysed using McNemar's test with Yates' continuity correction.

\section{Results}

The population evaluating the new products was tri-Service. 97 pre-course and 86 post-course questionnaires were completed.

$40 \%$ of respondents identified their current practice was to remove the nonstretch cotton bandages of a first field dressing and secure the pad with a crepe bandage (Table 1).

Following training $94 \%$ believed there was benefit from the new techniques (Table 2). $91 \%$ believed the elastic field dressing was an improvement over the traditional first field dressing. 98\% believed the combat application tourniquet was an improvement over the Samway tourniquet. $100 \%$ believed that the availability of QuikClot ${ }^{\mathrm{TM}}$ improved the effectiveness to control external bleeding (Table 3); 97\% believed the potential benefits of QuikClot ${ }^{\mathrm{TM}}$ outweighed the potential risks.

The change in confidence to manage difficult wounds likely to cause severe haemorrhage was highly significant for both a traumatic amputation and a deep ragged groin wound $(p<0.0001$ in each case) (Table 4).

$97 \%$ of respondents judged the novel techniques and education programme to be overall effective (Table 5). 
Table 1. Current practice of applying existing first field dressing (pre-course questionnaire).

\begin{tabular}{|l|l|}
\hline Use non-stretch cotton wings & 56 \\
\hline Cut off wings and use crepe bandage & 39 \\
\hline Not recorded & 2 \\
\hline
\end{tabular}

Table 2. Attitudes towards new techniques (post-course questionnaire).

\begin{tabular}{|l|l|l|l|}
\hline & $\begin{array}{l}\text { No benefit from } \\
\text { new techniques }\end{array}$ & $\begin{array}{l}\text { New field } \\
\text { dressing better }\end{array}$ & $\begin{array}{l}\text { New tourniquet } \\
\text { better }\end{array}$ \\
\hline Strongly agree & 2 & 50 & 61 \\
\hline Moderate agreement & 0 & 28 & 23 \\
\hline No opinion & 3 & 4 & 2 \\
\hline Moderate disagreement & 43 & 4 & 0 \\
\hline Strongly disagree & 38 & 0 & 0 \\
\hline
\end{tabular}

Table 3. Attitudes towards QuikClot (post-course questionnaire).

\begin{tabular}{|l|l|l|}
\hline & $\begin{array}{l}\text { Availability of QuikClot } \\
\text { improves effectiveness }\end{array}$ & $\begin{array}{l}\text { QuikClot benefits } \\
\text { outweigh potential risks }\end{array}$ \\
\hline Strongly agree & 47 & 38 \\
\hline Moderate agreement & 39 & 45 \\
\hline No opinion & 0 & 3 \\
\hline Moderate disagreement & 0 & 0 \\
\hline Strongly disagree & 0 & 0 \\
\hline
\end{tabular}

Table 4: Confidence in dealing with severe haemorrhage.

\begin{tabular}{|l|l|l|l|l|}
\hline & $\begin{array}{l}\text { Traumatic } \\
\text { amputation } \\
\text { (pre-course) }\end{array}$ & $\begin{array}{l}\text { Traumatic } \\
\text { amputation } \\
\text { (post-course) }\end{array}$ & $\begin{array}{l}\text { Deep ragged } \\
\text { groin wound } \\
\text { (pre-course) }\end{array}$ & $\begin{array}{l}\text { Deep ragged } \\
\text { groin wound } \\
\text { (post-course) }\end{array}$ \\
\hline Very confident & 6 & 40 & 0 & 31 \\
\hline Some confidence & 55 & 45 & 33 & 53 \\
\hline Neutral & 17 & 1 & 25 & 2 \\
\hline Little confidence & 16 & 0 & 32 & 0 \\
\hline No confidence & 3 & 0 & 7 & 0 \\
\hline Significance & $\mathbf{p}<\mathbf{0 . 0 0 0 1}$ & & $\mathbf{p}<\mathbf{0 . 0 0 0 1}$ & \\
\hline
\end{tabular}

Table 5. Overall effectiveness of new haemostatic training and techniques

\begin{tabular}{|l|l|}
\hline Very effective & 46 \\
\hline Moderately effective & 37 \\
\hline Neutral & 3 \\
\hline Minimal effect & 0 \\
\hline No effect & 0 \\
\hline
\end{tabular}




\section{Discussion}

The novel techniques and related education programme achieved a high degree of approval from the professional medical personnel trained immediately predeployment. For the small proportion who stated there was no benefit from the novel techniques $(2 \%)$ there was no specific reason annotated; this was contradicted by the fact there was a proportion who had no confidence to treat life-threatening haemorrhage pre-course, but all respondents demonstrated some degree of confidence post-course.

The current practice to use an elastic crepe bandage over the first field dressing confirms a lack of confidence in the existing dressing and a fundamental failure in its design to provide compression. Some personnel expressed concern that the new dressing may absorb less blood than the old. The relative fluid capacity of the two dressings has not been determined. Importantly, a high absorbency is not an indicator of an effective dressing. Blood is required in the patient, not the dressing. The effectiveness of a dressing should be measured by how it contributes to reducing or stopping blood loss through its compression effect over the wound.

Open media sources have illustrated how live animal models are used by US military to demonstrate the effectiveness of QuikClot ${ }^{\mathrm{TM}}$ and $\mathrm{HemCon}^{\mathrm{TM}}$ (an alternative haemostatic agent) to clinicians. The practical training of UK personnel relies on simulation, which can currently only be used to assess compliance with the sequence of actions, rather than demonstrate any effectiveness to arrest haemorrhage. Greater validity of training would come from a model that simulates control of bleeding. Where the sequence alone is tested, an inexpensive training substitute for QuikClot ${ }^{\mathrm{TM}}$ is required.

The operational imperative demanded the rapid development of a strategy for novel haemostatics, equipment procurement and the development of training. The Defence Systems Approach to Training (DSAT) has been applied to the programme retrospectively to validate the objectives, structure and content.

\section{Conclusion}

The training programme described has lead to improved confidence in the ability of individuals to deal with complex lifethreatening haemorrhage. This contributes to the "moral component" of the fighting force (1). The ongoing audit will investigate how this translates into clinical effectiveness in the field.

\section{Reference}

1. Joint Warfare Publication 4-03. Foint Medical Doctrine. Joint Doctrine and Concepts Centre. 